\title{
Analisis Respon Resistivitas Sampel Tanah TPA Ngipik Kabupaten Gresik Berdasarkan Uji Resistivitas Skala Laboratorium
}

\author{
Ahmad Qomaruddin Arsyadi ${ }^{1}$, Dwa Desa Warnana ${ }^{1}$, Nila Sutra ${ }^{2}$, dan Ria Asih Aryani Soemitro ${ }^{2}$ \\ ${ }^{1}$ Departemen Teknik Geofisika, \\ ${ }^{2}$ Departemen Teknik Sipil, \\ ${ }^{1,2}$ Fakultas Teknik Sipil dan Perencanaan, Institut Teknologi Sepuluh Nopember Surabaya (ITS) \\ e-mail:dwa_desa@geofisika.its.ac.id
}

\begin{abstract}
Abstrak-TPA Ngipik Kabupaten Gresik berdiri dengan sistem Open Dumping selama 14 tahun yang menyebabkan terjadinya pencemaran air tanah oleh air lindi. Untuk mendapatkan kontras yang jelas pada nilai resistivitas yang diduga sebagai sebaran air lindi, dilakukan pengujian resistivitas skala laboratorium. Pengujian ini ditujukan untuk mengetahui pengaruh fluida pada sampel tanah TPA Ngipik. Sampel tanah yang diuji yakni dua sampel dengan dibedakan fluida yang tersaturasi. Digunakan resistivitas dengan konfigurasi Wenner dengan jarak antar elektroda sebesar $1 \mathrm{~cm}$. Didapatkan hasil bahwa sampel A mengalami kejenuhan dan nilai resistivitas yang stabil pada penambahan aquades tetes ke-80. Sedangkan pada sampel $B$ mengalami kejenuhan dan nilai resistivitas yang stabil pada penambahan air lindi tetes ke-40. Nilai resistivitas sampel $B$ dengan kandungan air lindi lebih kecil daripada sampel A dengan kandungan air aquades. Sampel tanah lempung dengan kandungan air lindi lebih konduktif dibandingkan dengan kandungan air aquades.
\end{abstract}

Kata Kunci-Lindi, Resistivitas, Wenner, Skala Lab, Ngipik.

\section{PENDAHULUAN}

$\mathrm{T}$ PA Ngipik Kabupaten Gresik telah berdiri selama 14 tahun sejak tahun 2003. TPA Ngipik beroperasi dengan sistem pengelolaan sampah Open Dumping. Padahal dalam perencanaanya TPA ini didesain dengan sistem Sanitary Landfill [1]. Sanitary Landfill merupakan sistem pengelolaan sampah terpadu yang memiliki lapisan penahan untuk air lindi agar tidak meresap ke bawah permukaan tanah. Sedangkan sistem Open Dumping merupakan sistem pengelolaan sampah terbuka dan pembuangan secara langsung ditumpuk pada area tertentu [2].

Akibat diterapkannya sistem Open Dumping ini, maka terjadi penyebaran air lindi ke bawah permukaan secara masif. Penyebaran air lindi tersebut mengakibatkan terjadi pencemaran air tanah. Untuk dapat mengetahui sebaran air lindi di bawah permukaan, dapat digunakan Metode Geofisika yakni metode Resistivitas 2D. Metode Resistivitas 2D memanfaatkan sifat kelistrikan yang ada pada batuan atau tanah dan kontrasnya pada kandungan air lindi.

Namun kendala yang terjadi ialah kontras nilai resistivitas yang mengalami pencemaran tidak terlihat jelas. Hal ini dikarenakan tanah TPA Ngipik berupa lempung. Sehingga perlu dilakukan pengujian resistivitas skala laboratorium terhadap sampel tanah TPA Ngipik untuk mengetahui secara detail kontras resistivitas yang muncul. Pengujian skala laboratorium pada penelitian ini bertujuan untuk mengetahui pengaruh fluida pada sampel tanah lapangan penelitian yakni TPA Ngipik Kabupaten Gresik.

\section{DASAR TEORI}

\section{A. Geologi Regional}

Lokasi penelitian yakni TPA Ngipik masuk ke dalam peta geologi lembar Surabaya-Sapulu di mana pada wilayah regional tersebut terdapat struktur antiklin Sekarkurung. Pada Gambar 1 terlihat ada banyak struktur patahan yang berarah Tenggara-Barat Laut.

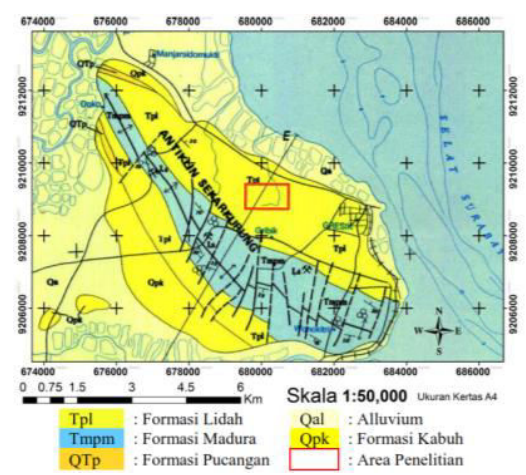

Gambar 1. Geologi Regional Area Penelitian [3].

Formasi dari muda ke tua ialah Alluvium dengan umur Quarter, Formasi Kabuh dengan umur Quarter, Formasi Pucangan dengan umur Quarter, Formasi Lidah dengan umur Tersier dan Formasi Madura dengan umur Tersier. Area penelitian yang ditunjukkan dengan kotak berwarna merah berada pada Formasi Lidah dengan susunan batulempung biru, batulempung kehitaman, sedikit kandungan fosil serta batulempung pasiran. Formasi Lidah memiliki karakteristik kandungan lempung yang tebal. Pada Gambar 1 tepat di area penelitian terdapat garis hitam yang memotong kotak merah merupakan garis irisan cross-section penampang geologi bawah permukaan [3]. 


\section{B. Sifat Kelistrikan Batuan}

Ketika batuan diberi aliran arus listrik, maka sifat kelistrikan batuan tersebut akan muncul. Sifat kelistrikan yang ada pada batuan ialah kemampuan mengalirkan arus listrik (konduktivitas) dan menghambat arus listrik (resistivitas / tahanan jenis). Berdasarkan kemampuan mengalirkan arus listrik, tahanan jenis batuan dibagi menjadi tiga bagian yakni:
a. Resistif : resistivitas $>10^{7} \Omega \mathrm{m}$
b. Semikonduktif : resistivitas $1-10^{7} \Omega \mathrm{m}$
c. Konduktif : resistivitas $10^{-8}-1 \Omega \mathrm{m}$

Tabel 1.

Tabel Resistivitas Batuan dan Material [4]

\begin{tabular}{|c|c|c|}
\hline Material & $\begin{array}{l}\text { Resistivitas } \\
(\Omega \mathrm{m})\end{array}$ & $\begin{array}{l}\text { Konduktivitas } \\
\text { (Siemens.m) }\end{array}$ \\
\hline \multicolumn{3}{|c|}{ Batuan Beku dan Metamorf } \\
\hline Granit & $5 \times 10^{3}-10^{6}$ & $10^{-6}-2 \times 10^{-4}$ \\
\hline Basalt & $10^{3}-10^{6}$ & $10^{-6}-10^{-3}$ \\
\hline Slate & $6 \times 10^{2}-4 \times 10^{7}$ & $2.5 \times 10^{-8}-1.7 \times 10^{-3}$ \\
\hline Marble & $10^{2}-2.5 \times 10^{8}$ & $4 \times 10^{-9}-10^{-2}$ \\
\hline Quartzite & $10^{2}-2 \times 10^{8}$ & $5 \times 10^{-9}-10^{-2}$ \\
\hline \multicolumn{3}{|c|}{ Batuan Sedimen } \\
\hline Batupasir & $8-4 \times 10^{3}$ & $2.5 \times 10^{-4}-0.125$ \\
\hline Batulempung & $20-2 \times 10^{3}$ & $5 \times 10^{-4}-0.05$ \\
\hline Batugamping & $50-4 \times 10^{2}$ & $2.5 \times 10^{-3}-0.02$ \\
\hline \multicolumn{3}{|c|}{ Tanah dan Air } \\
\hline Lempung & $1-100$ & $0.01-1$ \\
\hline Aluvial & $10-800$ & $1.25 \times 10^{-3}-0.1$ \\
\hline Air Tanah & $10-100$ & $0.01-0.1$ \\
\hline Air Laut & 0.2 & 5 \\
\hline
\end{tabular}

Tabel 1 di atas menunjukkan bahwa setiap jenis batuan memiliki nilai konduktivitas dan resistivitas yang berbedabeda. Hal ini dikarenakan material penyusunnya berbeda sehingga sifat kelistrikan yang dimiliki berbeda pula [4].

\section{Karakteristik Air Lindi}

Air lindi berasal dari hasil degradasi dan pencucian sampah akibat dari air hujan. Air lindi yang meresap ke bawah permukaan tanah akan mencemari air tanah. Sehingga akan timbul kontaminasi sifat fisik maupun sifat kimia dari air tanah yang membuat kualitas air menjadi turun [5].

Tabel 2 di bawah ini merupakan karakteristik air lindi yang berhubungan dengan sifat kimiawi [6].

Parameter-parameter yang ada pada Tabel 2 merupakan parameter umum yang biasa digunakan untuk membatasi kualitas air bersih dan air minum. Bila suatu TPA memiliki timbunan sampah organik yang besar maka akan dihasilkan air lindi dengan kandungan zat organik yang tinggi [7].

Tabel 2.

Karakteristik Air Lindi

\begin{tabular}{llc}
\hline \multicolumn{2}{c}{ Parameter } & \multicolumn{2}{c}{ Satuan } & Rentang \\
\hline $\mathrm{COD}$ & $\mathrm{mg} / \mathrm{liter}$ & $150-100.000$ \\
$\mathrm{BOD}_{5}$ & $\mathrm{mg} / \mathrm{liter}$ & $100-90.000$ \\
$\mathrm{pH}$ & - & $5,3-8,5$ \\
$\mathrm{~N}-$ Organik & $\mathrm{mg} / \mathrm{liter}$ & $1-2.000$ \\
\hline
\end{tabular}

\begin{tabular}{llc}
\hline \hline \multicolumn{1}{c}{ Parameter } & \multicolumn{1}{c}{ Satuan } & Rentang \\
\hline $\mathrm{N}$-Total & $\mathrm{mg} / \mathrm{liter}$ & $50-5.000$ \\
$\mathrm{Ca}$ & $\mathrm{mg} / \mathrm{liter}$ & $10-2.500$ \\
$\mathrm{Mg}$ & $\mathrm{mg} / \mathrm{liter}$ & $50-1.150$ \\
$\mathrm{Na}$ & $\mathrm{mg} / \mathrm{liter}$ & $50-4.000$ \\
$\mathrm{~K}$ & $\mathrm{mg} /$ liter & $10-2.500$ \\
\hline \hline
\end{tabular}

\section{Metode Resistivitas $2 D$}

Metode Resistivitas 2D merupakan jenis metode geofisika aktif dengan konsep menginjeksikan arus listrik ke bawah permukaan bumi dan mengukur beda potensial pada titik tertentu. Metode ini memanfaatkan sifat kelistrikan perlapisan bawah permukaan untuk mengetahui variasi tahanan jenis lapisan bumi (Telford et.al, 1990).

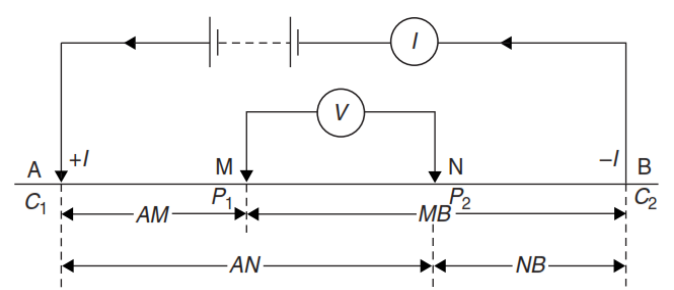

Gambar 2. Diagram Konsep Resistivitas 2D [8].

Gambar 2 di atas menjelaskan tentang dasar konsep pengukuran Resistivitas 2D. Pengukuran menggunakan dua elektroda sumber arus injeksi (A-B) dan dua elektroda pengukur tegangan (M-N). Dari posisi elektroda tersebut, dapat dihitung nilai resistivitas semu yang didapat dari pengukuran dengan persamaan di bawah ini:

$$
\rho=\mathrm{R} .2 \pi\left\{\left(\frac{1}{\mathrm{AM}}-\frac{1}{M B}\right)-\left(\frac{1}{\mathrm{AN}}-\frac{1}{N B}\right)\right\}^{-1}
$$

Konfigurasi yang digunakan dalam pengujian resistivitas yakni Wenner (Gambar 3). Hal ini dikarenakan konfigurasi ini sangat sederhana karena jarak antar elektroda pada konfigurasi Wenner sama. Sehingga penerapan dalam skala laboratorium lebih mudah [8]. Nilai faktor geometri (K) dari konfigurasi Wenner ialah sebagai berikut:

$$
K=2 \pi a
$$

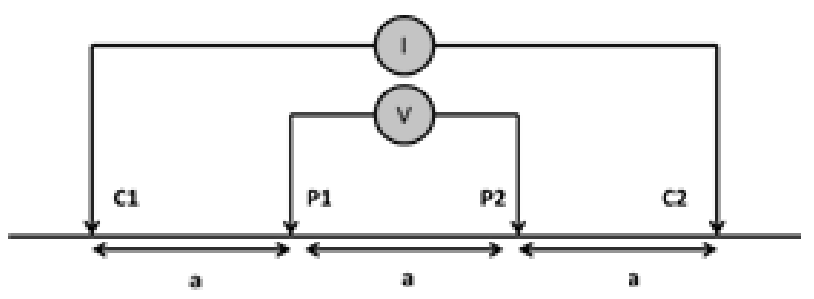

Gambar 3. Pemasangan Elektroda Konfigurasi Wenner [8]. 


\section{METODOLOGI PENELITIAN}

\section{A. Rancangan Penelitian}

Pembuatan Sampel Uji
- Sampel A
- Sampel B
Perlakuan (Fluida)
- Aquades (Sampel A)
- Air Lindi (Sampel B)
Pengukuran Resistivitas

- Konfigurasi Wenner

Gambar 4. Diagram Alir Penelitian.

Penelitian di awali dengan membuat dua sampel uji yang memiliki parameter yang sama. Selanjutnya masing-masing sampel diberi fluida yang berbeda sesuai dengan Gambar 4 . Setelah diberi tambahan fluida, dilakukan uji resistivitas pada masing-masing sampel.

\section{B. Pembuatan Sampel}

Tabel 3.

Parameter Pembuata Sampel Uji

\begin{tabular}{cccccc}
\hline $\begin{array}{c}\gamma_{\mathrm{d}} \\
\left(\mathrm{gr} / \mathrm{cm}^{3}\right)\end{array}$ & $\begin{array}{c}\mathrm{W}_{\mathrm{copt}} \\
(\%)\end{array}$ & $\begin{array}{c}\mathrm{W}_{\mathrm{t}} \\
(\mathrm{g})\end{array}$ & $\begin{array}{c}\mathrm{d} \\
(\mathrm{cm})\end{array}$ & $\begin{array}{c}\mathrm{t} \\
(\mathrm{cm})\end{array}$ & $\begin{array}{c}\mathrm{V} \\
\left(\mathrm{cm}^{3}\right)\end{array}$ \\
\hline \hline 1.32 & 30.50 & 136.53 & 3.72 & 7.27 & 78.98 \\
\hline \hline
\end{tabular}

Pembuatan sampel uji dilakukan dengan urutan sebagai berikut:

- Disiapkan tanah dari hasil pemboran

- Dikeringkan pada pancaran sinar matahari.

- Dilakukan uji proktor (menentukan berat kering).

- Dicetak sesuai dimensi pada Tabel 3.

- Dikeluarkan dari pipa cetakan

- Dimasukkan ke dalam pipa baru (dinding dilapisi lilin)

- Ditutup alas pipa dengan lilin

- Dilakukan pemboran 4 titik untuk posisi elektroda

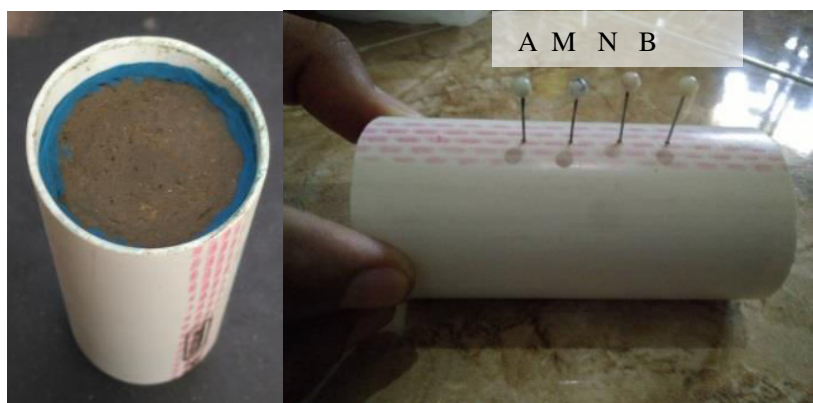

Gambar 5. Tampilan Sampel Uji (kiri) dan Posisi Pemasangan Elektroda (kanan).

\section{Pengujian Resistivitas}

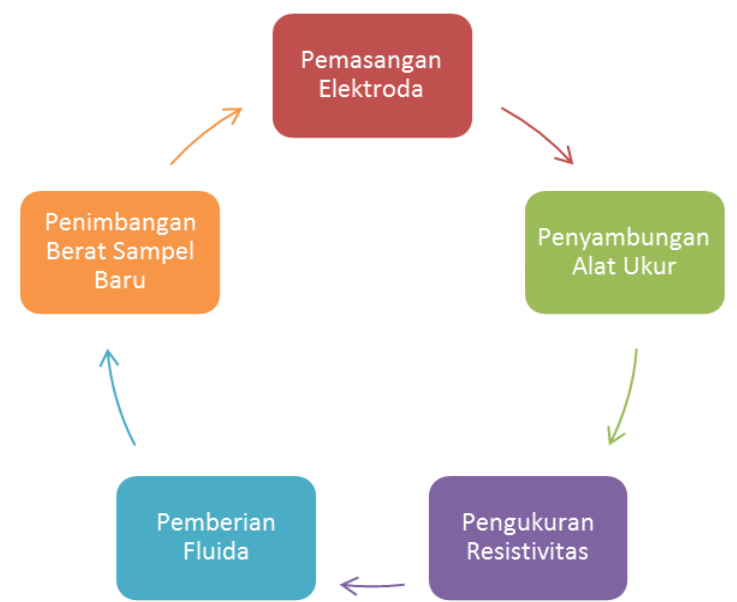

Gambar 6. Langkah Pengujian Resistivitas.

Penjabaran langkah pengujian resistivitas ialah sebagai berikut:

- Pemasangan elektroda pada lubang elektroda

- Penyambungan alat Resistivitimeter

- Pengukuran resistivitas dengan konfigurasi Wenner

- Pemberian Fluida (Aquades-A dan Air Lindi-B)

- Pelepasan Elektroda

- Penimbangan Berat Sampel Baru

- Kembali ke langkah awal.

\section{HASIL DAN PEMBAHASAN}

\section{A. Data Pengujian Resistivitas}

Dari proses pengukuran resistivitas pada sampel A dan sampel B, didapatkan data berupa berat sampel A dan B pasca penambahan fluida, perubahan berat kandungan fluida dan nilai resistansi dari kedua sampel. Tabel 4 di bawah ini menunjukkan hasil pengukuran resistivitas.

Tabel 4.

Data Hasil Pengukuran Resistivitas

\begin{tabular}{cccccc}
\hline \hline \multirow{2}{*}{ Tetes } & $\begin{array}{c}\text { Wk A } \\
(\mathrm{g})\end{array}$ & $\begin{array}{c}\text { Wk B } \\
(\mathrm{g})\end{array}$ & $\begin{array}{c}\Delta \mathrm{Wc} \\
(\mathrm{g})\end{array}$ & $\mathrm{R}_{\mathrm{A}}(\Omega)$ & $\mathrm{R}_{\mathrm{B}}(\Omega)$ \\
\hline 0 & 183.8 & 181.3 & 0 & 55.65 & 37.32 \\
10 & 184.2 & 181.7 & 0.4 & 50.83 & 34.47 \\
20 & 184.6 & 182.1 & 0.8 & 49.42 & 32.05 \\
30 & 185.1 & 182.6 & 1.3 & 48.21 & 28.66 \\
40 & 185.4 & 182.9 & 1.6 & 46.63 & 26.84 \\
50 & 185.7 & 183.2 & 1.9 & 45.64 & 26.59 \\
60 & 186.1 & 183.6 & 2.3 & 44.46 & 26.57 \\
70 & 186.6 & 184.1 & 2.8 & 43.36 & 26.44 \\
80 & 187 & 184.5 & 3.2 & 42.11 & 26.48 \\
90 & 187.3 & 184.8 & 3.5 & 42.11 & 26.50 \\
100 & 187.6 & 185.1 & 3.8 & 42.16 & 26.50 \\
\hline \hline
\end{tabular}

Dari Tabel 4 di atas, dapat dilihat bahwa nilai resistansi yang terukur ketika sampel belum diberi perlakuan sudah menunjukkan perbedaan antara sampel A dengan sampel B. Sampel A yang diberi air aquades memberikan respon 
resistansi yang lebih besar dibandingkan dengan sampel B yang diberi air lindi. Hal ini menunjukkan bahwa hambatan yang ada pada sampel A dalam mengalirkan arus listrik lebih besar dibandingkan dengan hambatan yang ada pada sampel B. Semakin banyak fluida yang diberikan pada masing-masing sampel, nilai resistansi yang terukur keduanya menurun. Hingga pada tetes ke-80 nilai resistansi yang terukur pada sampel A sudah mulai konstan. Sedangkan nilai resistansi yang terukur pada sampel B mulai konstan pada pemberian air lindi tetes ke-50. Tidak terjadinya perubahan resistansi yang cukup signifikan atau sudah stabil pada kedua sampel menunjukkan bahwa sampel sudah berada pada kandungan fluida maksimal dan sudah mengalami kejenuhan. Sehingga penambahan fluida selanjutnya tidak mempengaruhi nilai resistansi secara maksimal.

\section{B. Perubahan Resistivitas}

Data pengukuran berupa resistansi (R) selanjutnya dikalikan dengan faktor geometri dan didapatkan nilai resistivitas. Setiap perlakuan juga diukur penambahan berat sebagai perhitungan perubahan kandungan air pada sampel yang diuji. Setelah dilakukan pengujian dan perhitungan resistivitas, maka didapatkan hasil seperti pada Tabel 5 di bawah ini. Setiap perlakuan penambahan fluida dilakukan penimbangan berat akhir untuk mengetahui berat kandungan air yang diberikan. Dari data tersebut kemudian dihitung perubahan prosentase berat kandungan air di dalam sampel. Perhitungan resistivitas yang berupa hasil resistansi (R) dikalikan dengan faktor geometri didapatkan hasil yang semakin turun dengan kenaikan fluida yang ditambahkan. Namun penurunan nilai resistivitas tersebut tidak linear.

Tabel 5.

Hasil Perhitungan Prosentase Berat Kandungan Air dan Resistivitas

\begin{tabular}{ccccc}
\hline \hline Tetes & $\Delta \mathrm{Wc}(\mathrm{g})$ & $\Delta \mathrm{Wc}(\%)$ & $\rho \mathrm{A}(\Omega \mathrm{m})$ & $\rho \mathrm{B}(\Omega \mathrm{m})$ \\
\hline 0 & 0 & 30.50 & 3.49 & 2.34 \\
10 & 0.4 & 30.88 & 3.19 & 2.16 \\
20 & 0.8 & 31.27 & 3.10 & 2.01 \\
30 & 1.3 & 31.74 & 3.03 & 1.80 \\
40 & 1.6 & 32.03 & 2.93 & 1.69 \\
50 & 1.9 & 32.32 & 2.87 & 1.67 \\
60 & 2.3 & 32.70 & 2.79 & 1.67 \\
70 & 2.8 & 33.18 & 2.72 & 1.66 \\
80 & 3.2 & 33.56 & 2.64 & 1.66 \\
90 & 3.5 & 33.85 & 2.64 & 1.66 \\
100 & 3.8 & 34.13 & 2.65 & 1.66 \\
\hline \hline
\end{tabular}

Dari Tabel 5 di atas, dibuat sebuah grafik perbandingan antara perubahan resistivitas terhadap perubahan berat kandungan air aquades pada sampel A dan air lindi pada sampel B. Kedua grafik menunjukkan adanya penurunan dan titik stabil pada berat kandungan air tertentu.

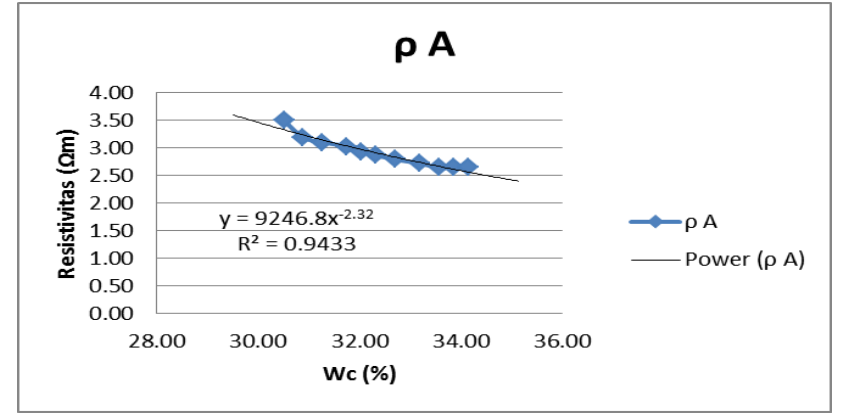

Gambar 7. Grafik Perubahan Resistivitas terhadap Perubahan Berat Kandungan Air Sampel A.

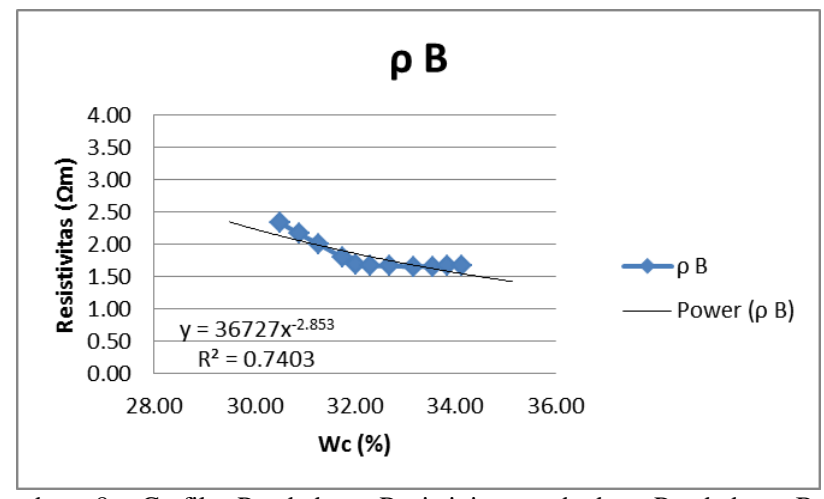

Gambar 8. Grafik Perubahan Resistivitas terhadap Perubahan Berat Kandungan Air Lindi Sampel B.

Perubahan resistivitas pada sampel B dengan kandungan air lindi lebih cepat menurun ketika penambahan fluida dilakukan dibandingkan dengan sampel $\mathrm{A}$. Hal ini disebabkan karena sifat air lindi yang lebih konduktif dari air aquades. Sehingga kejenuhan air lindi pada sampel juga lebih cepat. Pada masingmasing grafik dicari persamaan regresi power yang nantinya bisa digunakan untuk menghitung nilai resistivitas berdasarkan berat kandungan air pada data bor.

\section{KESIMPULAN}

Berdasarkan penelitian yang telah dilakukan, dapat diambil kesimpulan sebagai berikut:

- Rentang resistivitas hasil pengujian pada sampel A yakni $2.65-3.45 \Omega \mathrm{m}$.

- Rentang resistivitas hasil pengujian pada sampel B yakni $1.66-2.34 \Omega \mathrm{m}$.

- Pengaruh kandungan air lindi lebih besar dibandingkan dengan kandungan air aquades pada resistivitas.

Saran yang bisa diberikan untuk penelitian selanjutnya yakni pengujian skala laboratorium bisa dilakukan dengan metode pengujian lain yang lebih akurat, penambahan fluida dilakukan dengan suntikan ke dalam sampel secara langsung, pengujian bisa dilakukan dalam dimensi yang lebih besar untuk pengukuran resistivitas 2D agar kontras yang terjadi lebih terlihat.

\section{UCAPAN TERIMA KASIH}

Penelitian ini telah didanai oleh dana Hibah penelitian 
Pendidikan Magister menuju Doktor untuk Sarjana Unggul (PMDSU).

\section{DAFTAR PUSTAKA}

[1] BAPPEDA Kabupaten Gresik, "RPJMD Kabupaten Gresik Tahun 2016-2021," 2016.

[2] H. Widyatmoko and S. Moerdjoko, Menghindari, Mengolah dan Menyingkirkan Sampah. Jakarta: Abdi Tandur, 2002.

[3] Sukardi, "Peta Geologi Lembar Surabaya \& Sapulu, Jawa," Bandung, 1992.
[4] M. Loke, Tutorial: 2-D and 3-D Electrical Imaging Surveys. Malaysia, 2015.

[5] Y. Trihadiningrum, "Mikrobiologi Lingkungan," Surabaya, 1995.

[6] M. Ali, "Monograf Rembesan Air Lindi (Leachate)," Surabaya, 2011.

[7] R. Wulandari, "Identifikasi Pertambahan Persebaran Limbah Tempat Pembuangan Akhir (TPA) Jatibarang Menggunakan Metode Geolistrik," Universitas Negeri Semarang, 2015.

[8] J. M. Reynolds, An introduction to applied and environmental geophysics-Second Edition. United Kingdom: John Wiley \& Sons Ltd, 2011. 